\title{
Health Needs Assessment in the Nepalese Population in Brunei
}

\author{
NJ Mitchell
}

\begin{abstract}
The aim of this study was to try to identify significant differences between the current provision of medical care to the Nepalese community in Brunei and the ideal provision taking into account their cultural values. The Nepalese were found to be very willing to accept education on medical matters and a significant gap in their knowledge of modern medicine was confirmed. Their culture and social structure requires thought to be given to the sex of the medical personnel, the provision of joint consultations and the tolerance of traditional medical practices when providing medical care to such a population.
\end{abstract}

\section{Introduction}

There is a growing recognition that some understanding of peoples' religious beliefs and cultural values is required when providing medical care to a population from a different cultural background.

Many cultures, particularly in Asia, have great regard for the family unit and these may influence their decision making (1). Culture can also affect an individual's view of illness, health and death (2).

The providers of medical care are often aware of the need for such considerations. It has been shown in a previous study that a doctor's prescription habits are modified by the patient's ethnic group as well as other factors e.g. age, sex and social class (3).

In Brunei, the medical staff have experience of providing medical services for both British and Nepalese families. Experience gained by working with the Nepalese families confirmed the importance of understanding their culture before tailoring the available medical services to their needs. For this to be done efficiently it was necessary to try to highlight the areas in which the Nepali's requirements of the medical services differed from that of their British counterparts.

Maj NJ Mitchell MBChB MRCGP

Medical Centre RTMC, Chetwynd Barracks, Chilwell, Notts NG9 5NA

\section{Method}

Setting

The study was conducted at the Garrison Medical Centre in Seria, Brunei. The medical centre is responsible for the care of Nepalese and British soldiers and their dependants and is staffed with Nepalese and British health care workers.

\section{Recruitment of sample}

35 families who had recently arrived from Nepal were given the questionnaire to fill out on their initial contact with the medical centre. The questionnaire was collected on attendance for their medical screening that took place within the first month of residence in Brunei. Recruitment began in March 1997 and ended in June 1997.

\section{Questionnaire design}

To measure the needs of a population, the appropriate goals and deficiencies from these goals need to be identified (4). In an attempt to clarify these goals in our population of Gurkha families a qualitative questionnaire was devised. The questions tried to establish the family's social standing (by husband's rank), their religion, their family structure (number of children) and the level of the wife's education. It has been recognised that the mix of different professions appropriate in providing required medical services is very important in planning the provision of medical care (5). The questionnaire attempted to establish the family's attitudes to the health service currently provided compared to the family's ideal medical provision. In order to make the questionnaire understandable to the target population it was translated into Nepalese script by the Nepalese medical staff and then the responses translated by them back into English for analysis. The responses were correlated with broad headings to try to overcome the problems with translation. It was explained to all the participants that the purpose of the questionnaire was to provide a better service for them and that they were to answer honestly rather than give what they felt was the required response to the questions.

The translation of the Health Needs Questionnaire used follows:

\section{A Translation of the Health Needs Questionnaire}

Question 1. Do you always take medicine when you are unwell?

Question 2. Which type of treatment is most effective;

A. Tablets B. Liquid

C. Injection D. Ointment? 
Question 3. Which type of treatment do you prefer to take?

Question 4. What do you expect from the doctors?

Question 5. What do you expect from the midwives?

Question 6. What do you expect from SSAFA health visitors?

Question 7. Would you allow a male doctor to examine you?

Question 8. Would you prefer a male or female doctor to treat you?

Question 9. Do you want the following information;

A. Advice on a healthy diet

B. First aid in the home

C. Advice on cervical

screening

D. Advice on immunisation?

Question 10. Do you wish any additional health services e.g. antenatal classes, well woman clinic?

Question 11a. Do you consult the witch doctor?

Question 11b. Is this in addition to your medical practitioner?

Question 11c. What sort of problems can a witch doctor cure?

Question 12. Can doctors cure everything these days?

Question 13. How long should you breastfeed for?

Question 14. Do you make the decisions about your health or does your husband make them for you?

Question 15. Would you prefer to consult a doctor with your husband present?

\section{Results}

3 out of the 35 questionnaires had some questions unanswered. The answers were all appropriate to the questions despite translation. The questions were also framed so that the population could answer without feeling that they were criticising the existing service. It was emphasised that the aim of the questionnaire was to improve current medical services and therefore honesty in answering the questions was paramount. It was understood that the husband would be consulted before answering the questionnaire however in Nepalese culture all family decisions are made by the husband in a family unit.

The wives' ages ranged from 19-43 years with the average age of 28 years. $77 \%$ were Hindu and $17 \%$ Buddhist. ( 2 wives did not respond to this question.) The distribution of their husbands' rank was felt to be representative of the surveyed population (31\% Riflemen, $40 \%$ Junior NonCommissioned Officers, $17 \%$ Senior NonCommissioned Officers, 9\% Commissioned Officers). $74 \%$ were accompanying their husbands for the first time during his military service.

1 wife could not read, 6 could read and write English. Although 34/35 could read Nepalese, 11/35 could not read Nepalese in Roman script. This was significant as the Garrison had difficulty in producing information leaflets in Nepalese script.

Below is a summary of the results.

\begin{tabular}{|c|c|c|}
\hline $\begin{array}{l}\text { Question } \\
\text { No }\end{array}$ & $\begin{array}{l}\text { No. of } \\
\text { Participants }\end{array}$ & Response \\
\hline 1 & 32 & $\begin{array}{l}\text { Always took medication when they } \\
\text { felt ill. }\end{array}$ \\
\hline 2 & 25 & $\begin{array}{l}\text { Thought oral medication were most } \\
\text { effective }\end{array}$ \\
\hline 2 & 9 & $\begin{array}{l}\text { Thought injections were the most } \\
\text { effective }\end{array}$ \\
\hline 2 & 3 & $\begin{array}{l}\text { Thought all forms of medication } \\
\text { were effective }\end{array}$ \\
\hline 3 & 29 & Preferred to take oral medication \\
\hline 4 & 35 & $\begin{array}{l}\text { Expected the doctor to treat them, } \\
\text { with } 25 \text { expecting a cure }\end{array}$ \\
\hline 5 & 19 & Felt midwives' role was advisory \\
\hline 5 & 6 & $\begin{array}{l}\text { Felt midwives' role was that of an } \\
\text { interpreter }\end{array}$ \\
\hline 5 & 2 & $\begin{array}{l}\text { Felt midwives' role was that of a } \\
\text { doctor's assistant }\end{array}$ \\
\hline 5 & 4 & $\begin{array}{l}\text { Felt that midwives were practitioners } \\
\text { in their own right. }\end{array}$ \\
\hline 6 & 35 & $\begin{array}{l}\text { Felt SSAFA's roles were education } \\
\text { and child care }\end{array}$ \\
\hline 7 & 5 & $\begin{array}{l}\text { Would allow a male doctor to } \\
\text { examine them }\end{array}$ \\
\hline 8 & 34 & $\begin{array}{l}\text { Expressed a preference for a female } \\
\text { doctor }\end{array}$ \\
\hline 9 & $95 \%$ & $\begin{array}{l}\text { Positive response for health } \\
\text { promotion }\end{array}$ \\
\hline 10 & $50 \%$ & $\begin{array}{l}\text { Wanted additional medical support } \\
\text { e.g. well-woman clinics }\end{array}$ \\
\hline $11 \mathrm{a}$ & 17 & Attended the witch doctor \\
\hline $11 \mathrm{~b}$ & & All 17 also attended the doctor \\
\hline $11 \mathrm{c}$ & & $\begin{array}{l}\text { The witch doctor's role was to treat } \\
\text { mental problems and affairs of the } \\
\text { spirits. }\end{array}$ \\
\hline 12 & 8 & $\begin{array}{l}\text { Believed that doctors could cure } \\
\text { everything }\end{array}$ \\
\hline 13 & & $\begin{array}{l}\text { Length of time infants should be } \\
\text { breast-fed varied from } 6 \text { months to } 6 \\
\text { years }\end{array}$ \\
\hline 14 & 35 & $\begin{array}{l}\text { Wanted to discuss their health } \\
\text { problems with their husband }\end{array}$ \\
\hline 15 & 35 & $\begin{array}{l}\text { Wanted their husband present at a } \\
\text { consultation unless it involved an } \\
\text { intimate examination }\end{array}$ \\
\hline
\end{tabular}

\section{Discussion}

The results confirmed that there are some significant problems to be considered when providing medical care to Nepalese families. Although there were problems with translation at times, the results confirmed many of the personal experiences of individual medical practitioners. It should, also, be noted that all the participants had newly arrived from Nepal, many with limited experience of Western life. Many of their values and expectations of the medical services may alter with experience of western-like society.

It had been noted during consultations that the Nepalese expect medication to treat each of their symptoms and that oral medication had the best compliance. This was confirmed by our study. This has significant implications when trying to practice evidence based medicine.

Their knowledge of the skills of the primary health care team was poor and this 
needs to be addressed to enable the families to make better use of the midwives and health visitors.

The differences in culture make the women reluctant to visit a male doctor and this was borne out in the results to Qs $7 \&$ 8. This has a significant impact for manning of the medical centre. In the past when the practice had 2 male doctors women have failed to present intimate medical problems until late. Midwives have been used to perform intimate examinations in women too shy to allow a male doctor to examine them, however, they are not trained to pick up pelvic masses. In addition, the Nepali women do not consider the midwives to be practitioners in their own right.

The positive response to the offer of education was gratifying. The Nepalese have little awareness of the effect diet, alcohol and exercise can have on their health and preventative medicine is virtually unknown to the majority. Hopefully this can be improved through education.

They are also unrealistic in their views of what modern medicine can offer. This needs to be addressed by education. Our results suggest that the education (e.g. sexual health) provided to the soldiers is being passed onto the wives with positive results.

The Nepalese are known to be a superstitious people so it was not surprising that $48 \%$ attended their witch doctor even when modern medicine is freely available. The fact that they attend both practitioners is good and it is important to recognise that the witch doctor can have an important role in treating conditions that may not be amenable to therapeutics.

The difference in attitudes to health practices is illustrated by the breast-feeding habits of their nursing mothers. They have a $99 \%$ success rate of breast-feeding and often there are problems with trying to get them to stop which is sometimes necessary when the toddlers are failing to thrive as their main source of nutrition is still breast milk. This also can be addressed by education which is an important role provided by the health visitors.

A major difference in consulting practice is the reliance of the wife on the husband for decision making. The women will rarely make a decision about their health without consulting their husband first and this often means two or three consultations to discuss the same problems. If possible joint consultations should be offered particularly if there is a serious medical problem to discuss and it is often the husband who will make the eventual decision on the management rather than the wife. This illustrates the difference in social structure of the Nepalese and is not only acceptable to the wife, but desired.

\section{Recommendations}

The following recommendations were made on the basis of the results from this study.

1. A handout was prepared in Nepalese script to explain the role of the medical centre and the members of the primary health care team. This information would be reinforced verbally at the medical screening.

2. Health education leaflets in Hindu script were ordered from Department of Health in UK.

3. Classes teaching first aid, well-woman issues etc. were organised by the SSAFA health visitors.

4. The Armed Forces should try to have one female doctor in post at the medical centre while the garrison continues having Nepalese dependants.

\section{Acknowledgments}

I am grateful to the staff at MRS Seria for all their help and support during this study particularly the Gurkha midwives who carried out all the translation work and who inspired me to carry out the research.

\section{References}

1. Sugirtharjah $S$. The notion of respect in Asian Traditions. Br F Nursing 1994; 3(14): 739-41.

2. Wright $\mathrm{F}$, Cohen S, Caroselli C. How culture affects ethical decision making. Crit Critical Care Nursing Clinics of North America 1997; 9(1): 63-74.

3. Quershi B. Transcultural Medicine 2nd Edn. Kluwer Academic Publishers 1994.

4. Beven S, Stock J, Waite RK. Choosing an approach to reprofiling and manpower mix. Institute of Manpower Studies 1991.

5. Wilkin D, Hallam L, Doggett MA. Measures of need and outcome for primary health care. Oxford University Press 1992. 